\title{
THE REGULATION OF NATURAL MONOPOLIES GOES AHEAD MARKET DEVELOPMENT
}

\author{
G.Idrisov, E.Ponomareva
}

There are three most significant problems for infrastructure sectors of Russia's economy: determination the boundaries of markets for natural monopolies; considerable reduction the scale of cross-subsidization; and attraction of public and private capital into the infrastructure sectors. In this respect, the latest Government initiatives for establishing united natural monopolies regulator seem to outstrip market development. In our view, denoted problems rather than questions about the agency that should make the decisions on the regulation of natural monopolies should be overriding in government policy related to natural monopolies.

Developments in the regulation of natural monopolies (hereinafter - NM) in Russia have been actively discussed since the first half-year of 2013. In particular at that time appears the first proposals for a single regulator of NMs establishment. Especially in 2013 the Federal Tariff Service (FTS) prepared amendments to Federal Law of 17 August 1995, No 147-FZ 'On Natural Monopolies', whereby it was suggested that some of the functions of the Federal Antimonopoly Service (FAS) should be transferred to the $\mathrm{FTS}^{1}$. As a result, the Ministry of Economic Development of Russian Federation created special working group for Optimization and Structuring of the Powers and Functions of Federal Bodies of Executive Authority in the Sphere of NM Regulation. Its activity was expected to result in a proposal concerning the structure and functions of regulator(s) of NMs that is(are) able to implement government NM regulation policies with maximum efficiency ${ }^{2}$. Later on, the consideration of the issue of creating a single regulator of NMs was postponed due to the need to discuss the suggested regulator models $\mathrm{s}^{3}$, and then further delayed due to the worsening macroeconomic situation in mid-2014. In the first half-year of 2015, the Ministry of Economic Development of Russian Federation once again raised this issue, the formal reason was the necessity of saving budget funds and structuring of all types of control over the subjects of NM, elimination the duplicated activities performed by different government bodies of executive authority, and improvement the regula-

\footnotetext{
1 The alterations were not actually introduced; nevertheless, they created the context for discussing the idea of reforming the regulator.

2 In accordance with the materials prepared by the working group for Optimization and Structuring of the Powers and Functions of Federal Bodies of Executive Authority in the Sphere of NM Regulation under the Government of the Russian Federation, with due regard for the Promoting Competition and Improving Antimonopoly Policy Action Plan (Road Map).

3 For further detail, see the official government website for open government at http://open.gov.ru/events/5509474/.
}

tion process - among other things, in the framework of the general goal of ensuring better transparency of the activities of subjects of natural monopolies and reduction of their costs ${ }^{4}$.

It should be noted that attempts to increase transparency in the operation of subjects of NMs were made in the Concept for Working out and Developing the Mechanisms of Public Control over the Activity of Subjects of Natural Monopolies, with the Involvement of Consumers ${ }^{5}$; in the Action Plan (roadmap) regarding the Concept's implementation ${ }^{6}$; and in the Action Plan for Capping the Final Cost of Goods and Services Provided by Infrastructure Companies While Maintaining Their Financial Sustainability and Investment Attractiveness for 2013-2014 ${ }^{7}$. It was intended that implementation of the measures outlined in these documents, should boost the performance of subjects of NMs and promote the overall economic development and growth. As a result, over the period 2013-2014, the subjects of NMs began to cut their costs: the relevant companies reduced their investment programs, declined from adjustment of their costs, cut the working hours of their employees, and sell the non-core assets ${ }^{8}$. However, in the late of 2014, when the terms of trade changed and Russian companies could no longer get access to world financial markets, and the USA and

4 In accordance with the materials of the working group of the RF Ministry of Economic Development. As a result, in July 2015 the final decision to the effect that the regulation model for NM spheres be altered was adopted: on the basis of the existing government departments, a single regulator was to be created, while the Federal Tariff Service (FTS) was to become part of the Federal Antimonopoly Service (FAS).

5 Approved by Directive of the Government of the Russian Federation of 19 September 2013, No 1689-r.

6 Approved by Directive of the Government of the Russian Federation of 19 September 2013, No 1689-r.

7 Approved by Chairman of the Government of the Russian Federation Dmitry Medvedev of 11 November 2013, No 6732p-P9.

8 See the RF Ministry of Economic Development's official website at http://economy.gov.ru/minec/press/news/doc20140131_41; http://economy.gov.ru/minec/press/interview/doc20 130910_1. 
the EU introduced technological sanctions against Russia, the government policy towards NMs softened. It was suggested that their tariffs should be subject to indexation at a rate above the price indexes (CPI) predicted by the Ministry of Economic Development of Russian Federation (by applying the formula inflation +1 , where inflation equals $7.5 \%)^{1}$, while several subjects of NMs on the list of system-forming companies received additional government support (both financial and non-financial) ${ }^{2}$. Thus, in early 2015, an upward coefficient of $10 \%$ was applied to the tariffs set by OJSC Russian Railways, while even a higher ones were applied to export cargoes (OJSC Russian Railways may regulate export tariffs in the interval from $-12.8 \%$ to $+13.4 \%$ ), which could be explained by the increased costs of the company due to its tariffs had been frozen in 2014, resulted in profit decline at the same period.

Apparently there were several reasons behind the attempts for establishing a single regulator of NMs, including the necessity of the reduction of the costs of the government apparatus in the context of shortage of budget funds; elimination the duplicated responsibilities performed by different government departments due to lack of proper coordination between their policies towards NMs; and avoidance of incompetence of some governmental agencies involved in the regulation of NMs.

However, on the basis of our analysis of world experiences in NM markets regulation and the practices of market liberalization and competition promotion ${ }^{3}$, it

1 For further detail, see Report by Minister of Economic Development Alexey Ulyukaev on Russia's Socioeconomic Development Forecast for the Year 2015 and Planning Period 2016 and 2017 at http://economy.gov.ru/minec/press/ news/201409185; the scenario conditions, main parameters of the Russian Federation's Socioeconomic Development Forecast and the ceilings for the prices (or tariffs) for services provided by companies in the infrastructure sector for the year 2016 and planning period 2017 and 2018 (draft) at http://economy.gov.ru/wps/wcm/ connect/c804fd9b-7418-4f12-b075-9923e54ed9b4/\%D1\%F6\%E5 \%ED\%E0\%F0\%ED\%FB\%E5+\%F3\%F1\%EB\%EE\%E2\%E8\% FF 20162018. pdf?MOD=AJPERES\&CACHEID $=c 804 f d 9 b-7418-4 f 12-b 075-$ $9923 e 54$ ed9b4.

2 For more details on the criteria for and the forms of support, see the RF Ministry of Economic Development's official website at http://economy.gov.ru/minec/about/structure/depsectoreconom/2015031601.

3 For more details, see Joskow P. L. Regulation of natural monopoly // Handbook of law and economics. - 2007. - Vol. 2. P .1227-1348; Joskow P. L., Regulation and deregulation after 25 years: Lessons learned for research in industrial organization, // Review of Industrial Organization, 2005. P. 169-193; Pera A., Deregulation and privatization in an economy-wide context, // OECD Economic Studies, Vol. 12, 1989. P. 159-204; The Principles for the Governance of Regulators, OECD, 2013. http:// www.oecd.org/gov/regulatory-policy/governance-regulators.

htm\$; Recommendation of the Council on Regulatory Policy and Governance, OECD, 2012. http://www.oecd.org/regreform/regulatory-policy/49990817.pdf. can be concluded that efficient regulation of subjects of NMs can be achieved only after the markets deregulation or liberalization reforms, so that natural monopolies activities could be institutionally separated from the potentially competitive activities. Any efforts in inverted order (when first introduced the regulation procedures, and development is expected to come next) as a rule, can create the long-lasting barriers for the competition and development of nondiscriminatory access to the NMs services. Ultimately these barriers can become an obstacle to any further reform of subjects of NMs, as their corporate contours in the process of their adaptation to the existing regulation practices can become the 'seething pots' of poorly administered profits and losses. In the Russian situation this means that, before creating a united regulator of NMs, it would be essential to follow international best practices and to solve the most prioritized problems on the development of NMs markets:

1. It is necessary to outline the boundaries of natural monopoly markets. This problem will require the development of a consistent and predictable longterm policy, with clear definitions and separation of natural monopolies types of economic activities. This policy usually serves as a basis for determining the most appropriate forms of regulation to be applied to the NMs markets (for example, direct government control of some of subjects of NMs; or price-based and non-price regulation), access conditions to the NMs services, and the competitive conditions on the markets that to not belong to NMs.

World experience has demonstrated that countries are eventually able to determine exactly what is a NM, and what is not in the process of their development. Thus, for example, in the USA, the UK and Japan nearly all the sectors with an infrastructure component belong to the category of NM, while all the others have been liberalized. In the USA, shipper companies in the railway transport sector can cooperate with different cargo carriers, while the latter still operate their own infrastructures; during the liberalization reforms in the natural gas sector, a large number of local monopolies have emerged, which transport natural gas via their own pipeline networks. In the UK, as a result of deregulation in the natural gas sector, there now exist multiple natural gas suppliers that have established local monopolies in some regions and so, in addition to natural gas production, they also supply it to the final consumer. In the UK electric power industry, generation, transmission and distribution of electric power are now performed by different entities (and the generation companies are now competing).

At present, the long-run development prospects for each NM sector in Russia have not been ultimate- 
ly outlined yet. The concepts of reform in the three biggest sectors - the natural gas sector, the railway transportation sector, and the electric power industry differ fundamentally - from nearly complete separation of the generation function from transmission and supply, with the creation of quasi-markets for energy and power supply - that is the desintegration between the natural monopoly and competitive activities in the electric power industry, to complete absence of any subdivision in the natural gas sector. The principal model of the development of the railway transport sector have evidently already been made - the infrastructure operator has been separated from the carriers. However, the issue of creating the sources of longterm funding for infrastructure development, or at least establishing some transparent rules for the provision of the budget funding for this purposes, has not been resolved yet. As a result, any attempt for OJSC Russian Railways expenditures optimization produce only price increase for its services. One of the fundamental issues in the electric power industry is the tariff-setting mechanism for major industrial consumers. Now tariff has two parts: the tariff per production capacity unit of a given generator and the tariff per energy unit consumed. Initially it was expected that the introduction of this mechanism will create incentives for generators to reduce their energy capacity through modernization of the equipment. However, in practice, this mechanism pushed up the price of electric energy for big industrial end users. The most complicate situation can be observed now in the natural gas sector, where there are no common rules for the market operation (in terms of price regulation and access to infrastructure and export markets, with an uneven distribution of the social consumers and a lack of the regulation of the provision licensing, fiscal and regulatory preferences to different producers). The main choices in the development of that sector are to be made ${ }^{1}$; in fact, the primary regulator's task will be the definition of the competition patterns in natural gas production, transportation, storage and supply rather then its regulation.

2. It is necessary to reduce significantly the scale of cross-subsidization between different categories of consumers. Cross-subsidization arises when there is a difference between prices and the actual cost of production and delivery of goods (or provision of services). Most often, cross-subsidization occurs if there exist social preferences, when some consumers for some reasons are considered to be more important than all the other consumers (for example clinics and

1 See Gordeev D. S., Idrisov G. I., Karpel E. M. Theory and Practice for Natural Gas Pricing in Russia // Voprosy Ekonomiki [Issues of Economics] , 2015, No. 1, P. 80-102. hospitals). In a competitive market, when there is no market segmentation (no opportunities for implementation price-based consumer discrimination schemes), cross-subsidization is possible only on a limited scale, because some consumers will be mimicking subsidized group. The consequences of cross-subsidization is distortion of market incentives, which results in under- or overconsumption of certain goods or services.

In world practices, cross-subsidization often occurred in formation of railway transport tariffs for different cargo types, water-supply and water-disposal tariffs, surface transportation tariffs, and telecommunication tariffs for calls between different localities. For example, in the USA before deregulation in the telecommunications sector, tariffs for local calls were underpriced because all the costs of telecommunications networks unrelated to the traffic (amortization charges, interest payments, etc.) were charged to long-distance calls. In other countries - for example, in the UK - cross-subsidization in the telecommunications sector presented not only in tariffs for calls in different distances, but also in the tariffs for different types of consumers (small and large). In the UK watersupply sector cross-subsidization between regions and different consumer types had existed until the 1980s. Existence of cross-subsidization usually was explained by social reasons: consumers in different regions, other things being equal, must have comparable costs for NMs services no matter what the actual production costs of these services are ${ }^{2}$. During the liberalization of infrastructure sectors in the EU, the USA, Canada and Australia the scale of cross-subsidization declined, as the tariffs for the goods (or services) offered by these sectors began to be influenced by market mechanisms (and not by the factor of government social responsibilities to provide certain types of services to some consumer groups) and the raise the competition between different suppliers. Nevertheless, cross-subsidization still exists in some sectors, for example, postal service in the USA.

Now two types of cross-subsidization can generally be observed in all NMs sectors in the Russian economy: between household consumers and industrial consumers (prices for households are undervalued relative to actual production costs, and those for industry are overvalued); and between consumers located at different distances from the producers

2 For further detail, see Kaserman D. L., Mayo J. W., Flynn J. E. Cross-subsidization in telecommunications: Beyond the universal service fairy tale // Journal of Regulatory Economics. - 1990. V. 2. - No. 3. - P. 231-249; Joskow P. L., Regulation and deregulation after 25 years: Lessons learned for research in industrial organization // Review of Industrial Organization, 2005. P. 169193; Pera A., Deregulation and privatization in an economy-wide context // OECD Economic Studies, Vol. 12, 1989. P. 159-204. 
(prices for remote consumers usually are undervalued and overvalued for the consumers on short distances). Depending of the particular characteristics of a given sector, there are also other types of cross-subsidization: in the natural gas sector - between export and domestic consumers; in the electric power industry between energy and heating consumers; in the railway transport sector - between carriers of different cargo types. In a market economy, the rationality of using such a mechanism is strongly doubtful, because it distorts incentives for the efficient use of resources, reduces the modernization processes in the economy, and prevents optimization of the geographical distribution of production capacities. It is unlikely that the suggested single regulator of NMs will have a mandate to solve such types of problems. More likely, later on the most profitable market segments (by their product or geographical features) will become separate segments of free competitive market, while prices and tariffs in the remaining unprofitable market segments will have to be regulated as before.

3. It is necessary to create adequate conditions for attracting sustainable public and private investments to NMs markets. One distinctive feature of the NMs sectors is the high costs of development and support of their infrastructure. To cover these costs, it is necessary to find long-run funding sources, create incentives for efficient management of that funding and ensure long-term predictability of the regulation procedures applied to subjects of NMs to guarantee the repayment of the funds invested by the private sector.

As demonstrated by world practices, the problems associated with insufficient investment in infrastructure first of all arose in those countries where liberalization processes had led to the emergence of numerous local monopolies that supplied final goods (or services) to consumers and owned part of the existing infrastructure. Such companies, as a rule, have no incentives for developing and renewing their fixed assets. In face of rising demand this process results in infrastructure capacity deficit. Thus, when liberalization started in the 1980s in the UK electric power industry, results in separation of competitive and natural monopolies types of activities (with non-discriminatory access to the services for the NMs infrastructure). The innovation of that reform was the introduction, in the 1990s, of incentive regulation in place of standard rate of return regulation. The main goal of incentive regulation was to improve the operational performance and investment activity of the natural monopoly segments in electric energy industry. The idea of the new type of regulation was based on the fact that the regulated price (price cap) should incorporate a parameter that should stimulate these companies to improve their productivity similarly to companies operating in a free competitive market. Incentive pricing later began to be applied in other NMs sectors of the UK (and this practice exists until the present day) such as in the telecommunications, natural gas and water supply sectors ${ }^{1}$. In the USA, incentive pricing was introduced in the telecommunications, energy industry and some other sectors. One more way of attraction investment in infrastructure is RAB-regulation ${ }^{2}$. This method bases on the partial or full transfer of the costs of invested capital in the tariff ${ }^{3}$, as a guarantee that infrastructure companies will be able to cover their invested capital costs over a certain period of time (usually 35-40 years). This regulation method has been applied since the 1990s in the EU member states, the USA, Canada and Australia usually in the electric power industry and water supply sector.

The main part of the Russian infrastructure sectors are suffering from the shortage of funding for their capital expenditures, while the share of the investment component in tariffs is the cause of incessant disagreements between subjects of NMs and the regulatory agencies. In our opinion, a sustainable funding of the infrastructure sectors can be ensured only if a guaranteed investment component included in the tariff will cover the costs of servicing the loans needed for the investment programs and financing the depreciation costs. In other words, if a subject of NM needs to develop its infrastructure, it should attract funding from the financial market (through loans and/or infrastructure bonds or structured financial products, that can be bought by the government or the private sector), and then the cost of its servicing should be incorporated in their tariff. The parameters of such borrowing schemes should be coordinated with the regulator of NMs, that guarantees the presence of an investment component in the tariff though RAB or some other form of regulation. This simple and transparent rule will make unnecessary the annual discussions of such issues as the necessity of an additional contribution to the capital stock of a given subject of NM, appropriation some amount of money from the National Welfare Fund, or 'allowance' it to use its profits instead of paying the

\footnotetext{
1 For further detail, see Vogelsang I. Incentive regulation and competition in public utility markets: a 20-year perspective // Journal of Regulatory Economics. - 2002. - V. 22. - No. 1. - P. 5-27; Ai C., Sappington D. E. M. The impact of state incentive regulation on the US telecommunications industry // Journal of Regulatory Economics. - 2002. - V. 22. - No. 2. - P. 133-160; Crew M.A., Kleindorfer P. R. Incentive regulation in the United Kingdom and the United States: Some lessons //Journal of Regulatory Economics. 1996. - V. 9. - No. 3. - P. 211-225.

2 RAB is regulatory asset base.

3 Invested capital includes both the existing capital base that needs to be sustained and future investments (their timing and amount are usually to be agreed upon with the regulator).
} 
dividends due to the government. Of course, such a rule can be introduced only by the government rather than the regulator.

To sum it up, the regulatory policy of natural monopolies markets in every country traditionally gives rise to numerous problems of varying complexity and priority. In Russia, there are no clear long-run policy priorities for natural monopolies markets. The establishing of a new single united regulator or its establishment on the basis of the already existing bodies of executive authority is not reasonable in the present situation. Until the boundaries of natural monopolies are defined, and the markets around them are properly developed (or reformed), any attempts to introduce a 'new' regulation mode for subjects of NMs will hit existing problems and uncertainties. A 'megaregulator' can certainly be created quite easily by replacing signs on some government office doors, but we do not believe that these moves can really produce any qualitative changes in economic policy. There are many important development goals on the present-day agenda, which are beyond the competence of the NMs regulator. In other words, the top-priority goal in the sphere of natural monopolies should be the creation and development (or reform) of markets, followed by regulation reform - and not the other way round. 